\title{
Donovanosis in Australia: going, going...
}

\section{F J Bowden, on behalf of the National Donovanosis Eradication Advisory Committee*}

Sex Transm Infect 2005;81:365-366. doi: 10.1136/sti.2004.013227

In the 1990s donovanosis (or granuloma inguinale) had disappeared from most parts of the developed world. However, any practitioner working in the Northern Territory, far north Queensland, or the northern part of Western Australia would have been aware of the spectrum of morbidity associated with the condition in the Aboriginal and Torres Strait Islander population-ranging from mild genital ulceration to severe, disfiguring disease and disseminated, life threatening infection.

Series editor: David Lewis.

*For members of committee see end of paper.

Correspondence to: Francis J Bowden, MD National Donovanosis Eradication Advisory Committee, and Academic Unit of Internal Medicine and Canberra Sexual Health Centre, Australian National University Medical School, PO Box 11 Woden 2606 ACT, Australia; frank.bowden@ act.gov.au

Accepted for publication 14 December 2004
A pproximately 120000 Aboriginal and Torres Strait Islander people live in remote areas and their health outcomes are significantly poorer than their non-Indigenous counterparts. The continuing presence of a treatable condition such as donovanosis was yet another marker of the inequities of access to, and utilisation of, health services suffered by this population in remote Australia.

An apparent increase in the incidence of donovanosis in southern Africa and the recognition of the association between HIV transmission and genital ulcer disease rekindled Australian interest in the condition. ${ }^{1}$ In 1995, 36 cases were officially notified in the Northern Territory (NT), the principal endemic region, but active surveillance demonstrated that there were 115 prevalent cases that year. ${ }^{2}$ All the cases occurred in Aboriginal people.

Previously, treatment involved multiple daily doses of antibiotics for a prolonged period of time, but two studies in the NT demonstrated the value of azithromycin, which required only once daily dosing for a week or once weekly dosing for 4-6 weeks. $^{3}{ }^{4}$

Concurrently, a polymerase chain reaction (PCR) test was developed for the diagnosis of donovanosis, which could be performed on surface swabs of lesions and avoided the need for biopsy. ${ }^{5}$ The new understanding of the basic molecular biology gained from the PCR development led to reclassification of the causative organism from Calymmatobacterium granulomatis to Klebsiella granulomatis. ${ }^{6}$ The availability of a less invasive diagnostic method and new treatment with a greater likelihood of adherence increased the level of case finding and the number of people presenting with symptoms of the disease in central and northern Australia.

As part of the Tri-State HIV/STI initiative (a collaboration between the commonwealth and relevant state and territory health departments), a central Australian donovanosis project officer was employed in 1997 to coordinate the surveillance, diagnosis, and treatment of the condition in contiguous areas of the NT, South Australia, and Western Australia. Over the next 3 years, in the presence of enhanced surveillance, the notifications of donovanosis decreased dramatically in that region. ${ }^{7}$

A report commissioned by the Office for Aboriginal and Torres Strait Islander Health concluded that the eradication of donovanosis from Australia was an achievable and worthy goal $^{8}$ and in 2001 the then Commonwealth Minister for Health, Dr Michael Wooldridge, established the National Donovanosis Eradication Advisory Committee. The committee membership was broadly representative of government and non-government organisations and had laboratory, clinical, programme/policy, and epidemiological expert input. The project's goal was subsequently changed to "elimination" (defined as reduction to zero of the incidence of infection in a specified geographical area) since "eradication" would only be possible if a worldwide programme was undertaken. Elimination would be considered achieved when no new case of donovanosis had been notified to the National Notifiable Diseases Surveillance System (NNDSS) for 3 years. Setting a target for elimination of an STI was seen as a brave move in some quarters but was also recognised as a break from the sense of helplessness that can sometimes influence work in this arena.

Four project officers, one each in Western Australia and Queensland and two in the NT, were recruited to support the primary care services (both government and non-government), to develop educational materials, conduct in-services for staff in rural and remote areas, implement common protocols for treatment and diagnosis, and undertake active surveillance. The treatment protocols dealt with all causes of genital ulcer disease and advocated syndromic management. In two jurisdictions the project officers' activities were integrated into the work of local teams with public health responsibility for sexually transmitted infections (STI).

The number of new cases of donovanosis reported to the NNDSS continued to fall over the life of the project and at the time of writing only five cases had been reported in 2004 (see fig 1). This is the lowest number of notifications recorded since the commencement of accurate epidemiological data collection.

As the number of cases of donovanosis decreases, it will become increasingly difficult

Abbreviations: NNDSS, National Notifiable Diseases Surveillance System; NT, Northern Territory; PCR, polymerase chain reaction; STI, sexually transmitted infections 


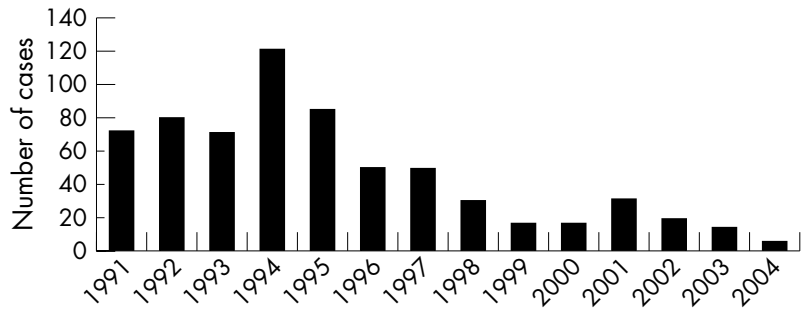

Figure 1 Notification of donovanosis to the Australian National Notifiable Diseases Surveillance System 1991-2004*. (*2004 data complete to the end of September.)

to maintain central and local interest in the condition. A possible direction for future public health interventions is to consider continuing the model of centralised officers with expertise in STIs who liaise with primary healthcare providers. This approach already operates in some state and territory jurisdictions (through the local public health and communicable diseases units). It makes sense in an environment of rapid staff turnover where it is very difficult to maintain a "corporate memory" of local disease patterns and where health practitioners are required to have skills in a broad range of disciplines rather than being specialised in STIs. National coordination and additional funding of an "STI initiative" endorsed by the Australian Government's National HIV and STI Strategy and the National Indigenous Australians' Sexual Health Strategy will be critical. A similar approach to STI control could be adopted in Australia's closest neighbour, Papua New Guinea, where donovanosis and other genital ulcerative conditions are endemic, although the rudimentary primary healthcare infrastructure in that country would hinder effective implementation.

In 1995, O'Farrell proposed a global eradication programme for donovanosis. ${ }^{9}$ We have taken up this idea in one geographic region and believe that the elimination of the disease in Australia is now probable. The project has been conducted in the context of an increasing incidence of genital herpes, an ongoing epidemic of syphilis, chlamydia, trichomoniasis, and gonorrhoea and early evidence of an emerging HIV epidemic in remote areas. We hope that our success so far with donovanosis, and the lessons learned, will aid in the development of strategies for the control of the other important (and more prevalent) STIs that affect Aboriginal and Torres Strait Islander people.

\section{ACKNOWLEDGEMENTS}

The author gratefully acknowledges the work and assistance of the National Donovanosis Eradication Advisory Committee project officers: Ms Noreen Conlon, Ms Anne Davis, Ms Brenda Henry, Ms Penny Marshall, Ms Janelle Wilkey, and Ms Chris Wilson; and OATSIH secretariat: Mr Bernard Pearce and Ms Bilawara Lee.

\section{THE NATIONAL DONOVANOSIS ERADICATION ADVISORY COMMITTEE (2004)}

Dr Ivan Bastian, Dr David Bradford, Dr Sophie Couzos, Mr Michael Howard, Professor John Kaldor, Mr Christopher Macaulay (representing Queensland, Northern Territory and Western Australian Health Departments), Associate Professor Cindy Shannon, Ms Patti Nona, Ms Joy Savage, and Dr Patricia Fagan.

\section{CONTRIBUTORS}

FB wrote the paper on behalf of the members of the National Donovanosis Eradication Advisory Committee; all members reviewed the text, made contributions to style and content, and the committee ratified the final version.

\section{REFERENCES}

$1 \mathrm{O}^{\prime}$ Farrell N, Hoosen AA, Coetzee KD, et al. Genital ulcer disease in men in Durban, South Africa. Genitourin Med 1991;67:327-30.

2 Mein J, Patel A, Bowden FJ. Surveillance of donovanosis in the Northern Territory. Venereology 1995;8:21-6.

3 Bowden FJ, Mein J, Plunkett C, et al. Pilot study of azithromycin in the treatment of genital donovanosis. Genitourin Med 1996;72:17-19.

4 Skov SJ, Tait P, Kaldor J, et al. A field trial of azithromycin in the treatment of donovanosis: a step towards eradication? Venereology 1997;11:11-14.

5 Carter J, Bowden FJ, Sriprakash KS, et al. Diagnostic polymerase chain reaction for donovanosis. Clin Infect Dis 1999;28:1168-9.

6 Carter JS, Bowden FJ, Bastian I, et al. Phylogenetic evidence for reclassification of Calymmatobacterium granulomatis as Klebsiella granulomatis comb nov. Int J Syst Bacteriol 1999:49:1695-700.

7 Miller PJ, Torzillo PJ, Hateley W. Impact of improved diagnosis and treatment on prevalence of gonorrhoea and chlamydial infection in remote aboriginal communities on Anangu Pitjantjatjara Lands. Med J Aust 1999;170:429-32.

8 Miller P. Donovanosis: control, or eradication? A situation review of donovanosis in Aboriginal and Torres Strait Islander population in Australia. Canberra: Commonwealth Department of Health and Ageing, 2001

9 O' Farrell N. Global eradication of donovanosis: an opportunity for limiting the spread of HIV-1 infection. Genitourin Med 1995;71:27-31. 